\title{
Dacryocystorhinostomy Stent Insertion in Initial Endoscopic Dacryocystorhinostomy
}

\author{
${ }^{1} \mathrm{SV}$ Manjunatha Rao, ${ }^{2} \mathrm{MM}$ Rajshekar
}

\section{ABSTRACT}

Aim: To study surgical outcome in dacryocystorhinostomy (DCR) stent insertion in initial endoscopic DCR and the complications associated with the surgery.

Study design: This is a prospective, single-blinded, randomized, controlled trial.

Materials and methods: The study was carried in a tertiary level center (period between November 2009 and February 2015). A total of 50 patients with epiphora due to nasolacrimal duct obstruction were divided randomly into two groups - with one group undergoing endoscopic DCR with stent and the other group undergoing endoscopic DCR without stent. The postoperative results were assessed subjectively and objectively after 3 and 6 months and also for complications of the procedure. The results were statistically analyzed by chi-square test.

Results: There was significant postoperative improvement across all participants and within both groups. A total of $92 \%$ of patients in the stent group and $84 \%$ of patients in the without stent group improved. There was no significant difference with respect to complications. Synechiae and secondary hemorrhage were the most common complications in the without stent group and stent group respectively.

Conclusion: The present study shows that statistically significant difference in results is not achieved by inserting stents initially. But, whenever there is excessive bleeding during surgery, which masks endoscopic picture, or when bony stoma created is small because of thick bone and poor access, when atrophic sac is present, or when adhesions are expected due to pus in sac, then stenting should be done without hesitancy. Best time to do stenting is when surgeons' first think of stenting. Regular postoperative follow-up is necessary as any defect like synechia and granulation tissue formation can be dealt with immediately.

Keywords: Endoscopic dacryocystorhinostomy, Epiphora, Lacrimal stents.

How to cite this article: Rao SVM, Rajshekar MM. Dacryocystorhinostomy Stent Insertion in Initial Endoscopic Dacryocystorhinostomy. Clin Rhinol An Int J 2016;9(3):120-124.

Source of support: Nil

Conflict of interest: None

\footnotetext{
${ }^{1,2}$ Associate Professor

${ }^{1}$ Department of ENT, Basaveshwara Medical College and Hospital, Chitradurga, Karnataka, India

${ }^{2}$ Department of Ophthalmology, Basaveshwara Medical College and Hospital, Chitradurga, Karnataka, India

Corresponding Author: SV Manjunatha Rao, Associate Professor, Department of ENT, Basaveshwara Medical College and Hospital, Chitradurga, Karnataka, India, Phone: +919620360677, e-mail: mrsarvade77@gmail.com
}

\section{INTRODUCTION}

Dacryocystorhinostomy (DCR) is a procedure performed to drain the lacrimal sac in cases of nasolacrimal duct obstruction. It can be performed externally or endoscopically. ${ }^{1,2}$ The evolution of lacrimal surgery began around $2250 \mathrm{BC}$, where the code of Hammurabi made first reference to surgical treatment of lacrimal fistula. ${ }^{3}$ In 1893 , Caldwell described the first intranasal DCR ${ }^{1-3}$; Donogh and Meiring described endoscopic DCR. ${ }^{2,3}$ Since then, many modifications have occurred in DCR surgeries. ${ }^{1,3}$ Currently, lacrimal stenting is done to enhance the results of the surgery. ${ }^{4}$ Presently, stenting is done in revision cases. On the other hand, some studies indicate that silicone stent itself is a reason for surgical failure due to granulation tissue formation and complications like punctual erosion and slitting of canaliculi. ${ }^{4}$ But now, good quality stents are available in the market, which rarely cause granulation and other problems. Hence, the study is carried out to know the surgical outcome of stenting at initial surgery so as to know whether good results can be obtained.

\section{AIM}

- To study the surgical outcome in DCR stent insertion in initial endoscopic DCR.

- To study the complications associated with surgery.

\section{MATERIALS AND METHODS}

\section{Study Subjects}

This is a prospective, single-blinded, randomized study conducted in a tertiary level center from November 2009 to February 2015.

The participants of the study are the patients who attended the outpatient department of the Department of Otorhinolaryngology and Ophthalmology. Ethical clearance was obtained from the ethical committee.

\section{Inclusion Criteria}

Inclusion criteria include patients with symptoms of nasolacrimal obstruction, which is not relieved by probing and syringing. 


\section{Exclusion Criteria}

- Patients with block proximal to nasolacrimal duct

- A patient with very gross deviated nasal septum on the same side where maneuvering with endoscope is not possible and requiring septoplasty

- Patients with nasal polyp

- Patients with atrophic rhinitis

- Patients having chronic sinusitis

- Patients with severe bony deformity of lacrimal sac fossa (posttraumatic)

- Revision cases.

All patients presented with history of epiphora. They were given antibiotics for 15 days prior to surgery. A detailed history was taken. The local eye examination and diagnostic nasal endoscopy were done. The patients were explained about the procedure, and written consent was obtained. The ophthalmologist performed probing and syringing. The computed tomography (CT) dacryocystogram was not done in any of the patients.

A total of 50 patients were randomly grouped into two groups of 25 each, one group for undergoing endoscopic DCR without stents and the other for endoscopic DCR with stents.

\section{Surgical Technique}

Premedication inj. Fortwin $30 \mathrm{mg}$ and inj. Phenergan $50 \mathrm{mg}$ were given half an hour prior to surgery intramuscularly, intragluteally. The procedure was performed under local anesthesia. The head end of the table was elevated to $30^{\circ}$, and the nose was packed with $4 \%$ xylocaine half an hour prior to the procedure. This gave mucosal anesthesia. Supratrochlear, supraorbital, infraorbital, and anterior ethmoidal nerve block was given with $1 \%$ xylocaine in 1:400,000 adrenaline. Local anesthesia was also injected near the axilla of uncinate process and maxillary line. Surgery was performed using 0 and 30 endoscopes. An inverted U-shaped incision was made in the lateral wall of the nasal cavity anterior and superior to the anterior attachment of middle turbinate with the help of sickle knife. The mucosal flap was elevated with Freer's elevator to expose the bone overlying the lacrimal sac. The mucosal flap was removed with the help of straight Blakesley forceps. The exposed bone, overlying the lacrimal sac, was gently drilled by cutting burr $(3 \mathrm{~mm})$ and with Kerrison rongeur. Bone was removed to the extent of approximately $1.0 \times 1.5 \mathrm{~cm}$, and lacrimal sac was exposed. Medial wall of the sac was incised with sickle knife and removed. Opening of the sac was confirmed by injecting $1 \%$ betadine solution. In 25 patients, the aurolac lacrimal intubation sets were passed through superior and inferior canaliculi, and ends of the tube were tied in the nose. Antibiotic ointment was applied in the eye. A small neomycin wick was kept in nose for 4 hours. All patients were discharged on regime of oral antibiotics and anti-inflammatory drugs and local antibiotic eye drops. Patients were followed up after 1 week, and then at 3 months and later at 6 months. Patient's lacrimal stent was removed at the end of the 3rd month in whom it had been inserted.

\section{Evaluation}

The Royal College of Ophthalmologists published guidelines for clinical governance, which suggests that freedom from epiphora 3 months after surgery is the marker for satisfactory procedure. ${ }^{5}$ Hence, subjective and objective assessments were done at the end of 3rd and 6th month interval.

Subjective evaluation was made by questionnaire in terms of complete/partial/no relief from symptoms. Objective evaluation was done by syringing at the end of 3rd and 6th month. Shrestha et al, ${ }^{2} \mathrm{Kakkar}$ et al, ${ }^{4}$ and Yung and Hardman-Lea ${ }^{6}$ have categorized the success rate of endoscopic DCR into complete cure, partial cure, and no improvement depending upon sac syringing. The present study also employs the same criteria for objective evaluation. The results were evaluated as follows:

- Complete cure means patent: There was no resistance to the flow of the fluid through sac to nasopharynx.

- Partial cure means partially patent: When some of the fluid regurgitated through the upper punctum and some passed into nasopharynx.

- No cure means blocked: When whole of the fluid regurgitated through the upper punctum and no fluid passed into the nasopharynx.

\section{Data Analysis}

Chi-square test was applied to evaluate the results; p-value of 0.05 was considered as statistically significant.

\section{RESULTS}

In the present study, the age group between 11 and 60 years was included. In endoscopic DCR without stent group, the youngest patient was 18 years and oldest was 54 years. In endoscopic DCR with stent group, the youngest patient was 19 years and oldest was 59 years. The majority of patients in both groups were between ages 40 and 50 years, i.e., $50 \%$.

In the present study, there were 15 males and 35 females, showing female predilection. A total of 15 patients underwent left-sided DCR and 10 patients underwent right-sided DCR in endoscopic DCR without stent group. In endoscopic DCR with stent group, 14 patients underwent left-sided DCR and 11 patients underwent right-sided DCR. 
Intraoperatively, in without stent group, mucoid discharge was seen in $12 \%(n=3)$, mucopurulent discharge was seen in $32 \%(n=8)$, purulent discharge was seen in $48 \%(n=12)$, and atrophic sac was seen in $8 \%(n=2)$ of patients. In stent group, mucoid discharge was seen in $8 \%(n=2)$, mucopurulent discharge was seen in $32 \%$ $(n=8)$, purulent discharge was seen in $44 \%(n=11)$, and atrophic sac was seen in 16\% $(n=4)$ of patients.

Subjectively, at 3 months in without stent group, 17 patients had complete relief, 6 patients had partial relief, and 2 patients had no relief. At the end of 6 months, 17 patients had complete relief, 4 patients had partial relief, and 4 patients had no relief. In patients with stent, at the end of 3 months, 25 patients had complete relief after the removal of stent. At the end of 6 months, 22 patients had complete relief, 1 patient had partial relief, and 2 had no relief. Chi-square values of 9.5 and 3.11 were obtained at the end of 3 and 6 months respectively (Table 1$)$.

Objectively, in patients without stent at the end of 3 months, 21 patients had complete cure, 2 had partial cure, and 2 had no cure. At the end of 6 months, 18 patients had complete cure, 3 had partial cure, and 4 had no cure. In patients with stent, at the end of 3 months, 23 had complete cure and 2 had no cure. After 6 months, 21 had complete cure, 2 had partial cure, and 2 had no cure. Chi-square values of 2.09 and 1.09 were obtained at the end of 3 and 6 months respectively (Table 2).

Regarding complications in without stent group, $12 \%$ $(\mathrm{n}=3)$ had synechia as the most common complication, $8 \%(\mathrm{n}=2)$ had secondary hemorrhage, and $8 \%(\mathrm{n}=2)$ had rhinostomy closure at the end of 6 months. In stent group, secondary hemorrhage occurred in $12 \%(n=3)$ of patients followed by difficulty in removal of stent in $4 \%$ $(n=1)$ of cases.

\section{DISCUSSION}

Endoscopic DCR is a commonly performed operation in which a fistulous tract is created between the lacrimal sac and the nasal cavity in order to relieve the epiphora due to nasolacrimal duct obstruction. Wormald ${ }^{7}$ had demonstrated that approximately two thirds of the lacrimal sac is above the axilla of the middle turbinate. Therefore, during DCR surgery, in order to accomplish complete sac exposure, a large amount of thick bone over the axilla of the middle turbinate and the lateral wall of the agger nasi has to be removed. The size of the lacrimal ostium created during endoscopic DCR is paramount to the success of this surgery. ${ }^{1}$ There are other factors like accurate anatomical knowledge of lacrimal sac area, which governs the result of the surgery. Studies of intranasal anatomy of the lacrimal sac have shown that the rhinostomy needs to be larger and higher on the lateral wall than previously thought; as a result, the upper half of the sac is behind the thick bone of the frontal process of the maxilla. ${ }^{1}$

Silicone stent has been proposed to maintain the patency of fistula during postoperative healing period. ${ }^{4}$ According to Al-Qahtani ${ }^{8}$, there remains no definitive proof that stenting improves outcomes after endoscopic DCR. In Vishwakarma et al ${ }^{3}$ study, endoscopic DCR with stenting had better results. Callejas et $\mathrm{al}^{9}$ advocate a selective stenting approach for primary endoscopic DCR, whereby stents are only inserted when a tight common canaliculus opening is found during surgery.

Table 1: Subjective assessment in patients with and without stent insertion

\begin{tabular}{|c|c|c|c|c|c|}
\hline Subjective relief & & $\begin{array}{l}\text { Without stent } \\
(n=25)\end{array}$ & $\begin{array}{l}\text { With stent } \\
(n=25)\end{array}$ & Chi-square test & $p$-value \\
\hline \multirow[t]{3}{*}{ At 3 months } & Complete relief & 17 & 25 & 9.5 & $<0.008$ \\
\hline & Partial relief & 6 & 0 & & \\
\hline & No relief & 2 & 0 & & \\
\hline \multirow[t]{3}{*}{ At 6 months } & Complete relief & 17 & 22 & 3.11 & NS \\
\hline & Partial relief & 4 & 1 & & \\
\hline & No relief & 4 & 2 & & \\
\hline
\end{tabular}

NS: Nonsignificant

Table 2: Objective assessment in patients with and without stent insertion

\begin{tabular}{llllll}
\hline Objective improvement & & $\begin{array}{l}\text { Without stent } \\
(n=25)\end{array}$ & $\begin{array}{l}\text { With stent } \\
(n=25)\end{array}$ & Chi-square test & -value \\
\hline At 3 months & Complete cure & 21 & 23 & 2.09 & NS \\
& Partial cure & 2 & 0 & & \\
At 6 months & No cure & 2 & 2 & 1.09 & NS \\
& Complete cure & 18 & 21 & \\
& Partial cure & 3 & 2 & \\
\hline
\end{tabular}

NS: Nonsignificant 
Singh et al, ${ }^{10}$ Sham and van Hasselt,, ${ }^{11}$ Acharya et al, ${ }^{12}$ and Kakkar et $\mathrm{al}^{4}$ on the basis of their studies opined that silicone stenting is not routinely indicated in endoscopic DCR, as there was no difference with stent and without stent. Additionally, the use of stent is associated with patient discomfort, increased risk of complications, and additional cost. ${ }^{4}$

In the present study, the majority of patients in both groups were between ages 40 and 50 years. In the study of Vishwakarma et al, ${ }^{3}$ most of them were in the age group of 31 to 50 . In Harvinder et $\mathrm{al}^{1}$ study, the mean age was 45.54 years (18-74 years). In Kakkar et al ${ }^{4}$ study, the age of the patients ranged from 16 to 60 years, with the most common age group affected being 21 to 30 years. The mean age in the study was 33.8 years.

In the present study, there were 15 males and 35 females, showing female predilection. This correlates with other studies. In Vishwakarma et $\mathrm{al}^{3}$ study, there were $73.2 \%$ of females and $26.8 \%$ of males. In Harvinder et $\mathrm{al}^{1}$ study, there were $66.6 \%$ of females and $33.3 \%$ of males. In Kakkar et $\mathrm{al}^{4}$ study, there were $71 \%$ of females and $29 \%$ of males.

In the present study, 29 patients underwent left-sided DCR, and 21 patients underwent right-sided DCR. In Harvinder et $\mathrm{al}^{1}$ study, 13 patients underwent left-sided DCR, 7 right-sided DCR, and 2 bilateral DCR.

In the present study, the success rate of endoscopic DCR without stent is around $84 \%$. Failure occurred in 2 patients with synechia and 2 patients with closed rhinostoma. Closure of the rhinostomy opening was considered a major factor for surgical failure in DCR. The success rate of endoscopic DCR without stent reported in the literature varies from 90 to $96 \%$ compared with the present study. Singh et $\mathrm{al}^{10}$ reported success rate of $92.6 \%$ of endoscopic DCR without stent. Callejas et $\mathrm{al}^{9}$ reported $81 \%$ success without stent. Kakkar et $\mathrm{al}^{4}$ reported $90 \%$ success without stent. Yeon and Shim ${ }^{13}$ reported $93.3 \%$ success rate in the without stent group. ${ }^{13}$

In the present study, the success rate of endoscopic DCR with stent is $92 \%$ at the end of 6 months. Jin et $\mathrm{al}^{5}$ reported primary success rate of $83 \%$ with endoscopic DCR with stent. Sprekelson ${ }^{14}$ reported success with endoscopic DCR with stent in $85 \%$ patients. Callejas et $\mathrm{al}^{9}$ reported $82.5 \%$ success with stents, and in Kakkar et $\mathrm{al}^{4}$ study, the success rate was $85 \%$ with stent. Yeon and Shim ${ }^{13}$ reported $83 \%$ success in the stent group.

The synechia formed in the nonstent group was released under the guidance of endoscope. Secondary hemorrhage, which occurred in both groups, was managed conservatively by nasal packing for 24 hours. Closure of rhinostomy occurred in 2 patients, and one among the two also had secondary hemorrhage. They were advised revision surgery. In stent group, secondary hemorrhage occurred in $12 \%$ of patients. This occurred in initial cases owing to learning curve while passing the metallic end of the stent, which caused abrasions in nasal mucosa. Difficulty in removal of stent occurred in 1 patient whose nasal end of stent was small. Postoperative discomfort, orbital fat exposure, corneal abrasion, canaliculi erosion, and tube prolapse from stent never occurred in the present study as high-quality stent was used with gentle handling.

In Kakkar et $\mathrm{al}^{4}$ study, minor bleeding from the operative site occurred in 2 patients: 1 patient (10\%) with stent and 1 patient (5\%) without stent. Difficulty in stent removal was observed in 1 patient and in another patient spontaneous extrusion of stent was seen at 2 weeks.

In Harvinder et $\mathrm{al}^{1}$ study, 2 patients had complications, one orbital fat exposure and the other had secondary hemorrhage. In Kakkar et $\mathrm{al}^{4}$ study, difficulty in stent removal was observed in 1 patient, as stent could not be removed completely due to the formation of granulations. Spontaneous extrusion of stent was seen in 1 patient at 2 weeks. Jin et $\mathrm{al}^{5}$ reported that $17 \%$ of rhinostomy opening was found to be obstructed by granulations or synechia in endoscopic DCR with stent. He reported bleeding from nasal cavity, orbital injury, CSF leakage through fractured ethmoid, corneal abrasion, canaliculi erosion due to overly tight silicone tube placement, and lacrimal pump syndrome associated with the use of stent.

\section{CONCLUSION}

The present study shows that statistically significant difference in results is not achieved by inserting stents initially. But, whenever there is excessive bleeding during surgery that masks endoscopic picture or when bony stoma created is small because of thick bone and poor access, when atrophic sac is present, or when adhesions are expected due to pus in sac, then stenting should be done without hesitancy. Best time to do stenting is when surgeons first think of stenting. Regular postoperative follow-up is necessary, as any defect like synechia and granulation tissue formation can be dealt with immediately.

\section{REFERENCES}

1. Harvinder S, Rosalind S, Philip R, Mallina S, Gurdeep S. Powered endoscopic dacryocystorhinostomy with mucosal flaps without stenting. Med J Malaysia 2008 Aug;63(3): 237-238.

2. Shrestha S, Kafle PK, Pokhrel S, Maharjan M, Toran KC. Successes rate of endoscopic dacryocystorhinostomy at KMC Kathmandu University. Med J 2010;8(2):195-198. 
3. Vishwakarma R, Singh N, Ghosh R. A study of 272 cases of endoscopic dacryocystorhinostomy. Indian J Otorhinolaryngol Head Neck Surg 2004 Oct;56(4):259-261.

4. Kakkar V, Chugh J, Sachdeva S, Sharma N, Ramesh. Endoscopic dacryocystorhinostomy with and without silicone stent: a comparative study. Internet J Otorhinolaryngol 2009;9(1):2-3.

5. Jin HR, Yeon JY, Choi MY. Endoscopic dacryocystorhinostomy: creation of a large marsupialized lacrimal sac. J Korean Med Sci 2006 Aug;21(4):719-723.

6. Yung MW, Hardman-Lea S. Analysis of the results of surgical endoscopic dacryocystorhinostomy: effect of the level of obstruction. Br J Ophthalmol 2002 Jul;86(7):792-794.

7. Wormald PJ. Powered endonasal dacryocystorhinostomy. Laryngoscope 2002;112:69-71.

8. Al-Qahtani AS. Primary endoscopic dacryocystorhinostomy with or without silicone tubing: a prospective randomized study. Am J Rhinol Allergy 2012 Jul;26(4):332-334.
9. Callejas CA, Tewfik MA, Wormald P-J. Powered endoscopic dacryocystorhinostomy with selective stenting. Laryngoscope 2010 Jul;120(7):1449-1452.

10. Singh M, Jain V, Gupta SC, Singh SP. Intranasal endoscopic DCR (END-DCR) in cases of dacryocystitis. Ind J Otolaryngol Head Neck Surg 2004 Jul;56(3):177-183.

11. Sham CL, van Hasselt CA. Endoscopic terminal dacryocystorhinostomy. Laryngoscope 2000 Jun;110(6):1045-1049.

12. Acharya K, Pradhan B, Thapa N, Khanal S. Comparison of outcome following endoscopic dacryocystorhinostomy with external dacryocystorhinostomy. Nepalese J ENT Head Neck Surg 2011 Jul-Dec;2(2):2-3.

13. Yeon JY, Shim WS. Endoscopic dacryocystorhinostomy without silicone stent. Acta Otolaryngol 2012 Jun;132(1): 77-81.

14. Sprekelson MB. Endoscopic dacryocystorhinostomy - surgical techniques and results. Laryngoscope 1996 Feb;106(2 Pt 1): 187-189. 